\title{
Glutathione Monoethyl Ester Ameliorates Caerulein-induced Pancreatitis in the Mouse
}

\author{
Brent A. Neuschwander-Tetri, ${ }^{\star}$ Linda D. Ferrell, R. J. Sukhabote, ${ }^{\star}$ and James H. Grendell* \\ Departments of *Medicine and ${ }^{\ddagger}$ Pathology, University of California San Francisco, San Francisco, California 94143; \\ and *Medical Service, San Francisco VA Medical Center, San Francisco, California 94121
}

\begin{abstract}
Studies in animal models suggest that oxygen radicals may be important in the pathogenesis of acute pancreatitis. Because glutathione is an essential component of the defense against radical-mediated cellular injury, we investigated whether pancreatic glutathione content is influenced by inducing acute pancreatitis and whether augmenting the intracellular supply of glutathione would alter the course of pancreatitis. Caerulein, a decapeptide cholecystokinin analogue, induces acute necrotizing pancreatitis in mice when given in high doses $(50 \mu \mathrm{g} / \mathrm{kg}$ per h) over a period of $6 \mathrm{~h}$. The pancreatic glutathione content (total, GSH + GSSG) in mice treated with high-dose caerulein fell to $17 \%$ of normal within $4 \mathrm{~h}$ of beginning caerulein and recovered toward normal after discontinuing caerulein treatment. Mice treated with glutathione monoethyl ester (20 mmol/kg $1 \mathrm{~h}$ before caerulein, $10 \mathrm{mmol} / \mathrm{kg} 3$ and $7 \mathrm{~h}$ after starting caerulein) were found to have blunted depletion of pancreatic glutathione, diminished histologic evidence of pancreatitis (necrosis, inflammation, and vacuolization), and lower serum amylase values compared with mice treated with caerulein alone. These findings suggest that the profound depletion of pancreatic glutathione caused by hyperstimulation of the pancreas with caerulein is critically important in the pathogenesis of acute caerulein-induced pancreatitis. (J. Clin. Invest. 1992. 89:109-116.) Key words: free radicals $\bullet \gamma$-glutamyltranspeptidase $\bullet$ AT125 $\bullet$ amylase $\bullet$ mouse
\end{abstract}

\section{Introduction}

Acute pancreatitis is a destructive process of the pancreas that can lead to severe illness and even death. Although a number of seemingly diverse causes of acute pancreatitis are recognized clinically, the events occurring at the molecular level leading to self-destruction of this organ have not been fully defined in humans or in experimental animal models (1). Because of this

Preliminary reports presented in abstract form at the Annual Meeting of the American Pancreatic Association, November 1989, (Pancreas. 4:633, 1989), the Annual Meeting of the American Gastroenterological Association, May 1990 (Gastroenterology. 98:A236, 1990), and the Annual Meeting of the American Gastroenterological Association, May 1991 (Gastroenterology. 100:A292, 1991).

Address correspondence to Brent A. Neuschwander-Tetri, M.D., Division of Gastroenterology and Hepatology, 3635 Vista Ave., St. Louis University Medical Center, St. Louis, MO 63110.

Received for publication 29 May 1991 and in revised form $22 \mathrm{Au}$ gust 1991.

J. Clin. Invest.

(c) The American Society for Clinical Investigation, Inc.

0021-9738/92/01/0109/08 \$2.00

Volume 89, January 1992, 109-116 incomplete understanding, rational treatments aimed at preventing pancreatitis or limiting the progression of ongoing disease are unavailable and the best current therapy relies solely on nonspecific supportive measures (2).

To further define the cellular and molecular events leading to tissue injury in acute pancreatitis, a number of experimental models have been developed and exploited over the past decade. Caerulein, a decapeptide cholecystokinin analogue, causes acute pancreatitis in rats (3) and mice (4) when given in supraphysiologic doses. Evidence of tissue injury occurs rapidly in this model: pancreatic vacuolization is found within $\mathbf{3 0}$ min (5), progressing to marked inflammation and tissue necrosis after $6 \mathrm{~h}$ of continuous caerulein administration (4). Despite the well-defined histologic and biochemical progression of pancreatitis in this experimental model as well as others, the intracellular events leading to cell injury and necrosis remain inadequately defined. Abnormal activation and intracellular release of the normally inactive precursor forms of the pancreatic digestive enzymes has been proposed as one process that may be important in the pathogenesis of acute pancreatitis $(5,6)$. Another line of evidence derived from several models of experimental pancreatitis suggests that oxygen radicals could also be important in mediating pancreatic injury (7-9). A logical corollary to the oxygen radical theory of pancreatitis is that the endogenous antioxidant defense mechanisms of the pancreatic acinar cell serve a critically important role in preventing the onset or diminishing the progression of pancreatitis. One essential element of the intracellular defense against reactive oxygen species is glutathione, the most abundant nonprotein sulfhydryl in the cell. By reacting directly with electrophilic compounds and by serving as a reductant for the elimination of hydrogen peroxide and lipid hydroperoxides, glutathione plays a vital role in the defense against reactive electrophilic metabolites and oxidant stress.

We investigated the status of pancreatic glutathione during the development of acute pancreatitis by using the caerulein model to determine what alterations, if any, in the glutathione status might occur during the evolution of pancreatitis and what effect augmenting endogenous glutathione levels might have on the progression of pancreatitis in this experimental model.

\section{Methods}

Materials. AT125 was a gift from Upjohn (Kalamazoo, MI). Glutathione monoethyl ester was synthesized as the free base by the method of Campbell and Griffith (10). All other reagents were obtained from Sigma Chemical Co. (St. Louis, MO).

Induction of pancreatitis. Female Swiss Webster mice weighing 12$14 \mathrm{~g}$ were administered either saline or caerulein injections hourly (50 $\mu \mathrm{g} / \mathrm{kg}$ s.c.) seven times. In the studies of dose response to caerulein, a dose of 0.1 or $5.0 \mu \mathrm{g} / \mathrm{kg}$ was administered on the same schedule. Water 
was provided ad lib. The animals were fasted for $12 \mathrm{~h}$ before beginning caerulein and through the duration of the experiment.

Administration of drugs. Animals treated with glutathione monoethyl ester were given $20 \mathrm{mmol} / \mathrm{kg}$ or saline vehicle i.p. $1 \mathrm{~h}$ before the first caerulein dose and twice thereafter at a dose of $10 \mathrm{mmol} / \mathrm{kg}$ at 4-h intervals. Animals treated with AT 125 were given $30 \mathrm{mg} / \mathrm{kg}$ s.c. beginning $5 \mathrm{~h}$ before the first caerulein dose and every $4 \mathrm{~h}$ thereafter for a total of five injections.

Preparation of tissues. At various time points after the first caerulein injection, animals were anesthetized with ether and pancreatic tissue was removed for glutathione, DNA, ATP, and $\gamma$-glutamyltranspeptidase $(\gamma \mathrm{GT})^{1}$ measurements. Liver samples were obtained simultaneously for glutathione measurement and kidney samples were obtained for $\gamma$ GT measurement. Tissue samples for glutathione measurement were frozen immediately in liquid nitrogen and stored at $-70^{\circ} \mathrm{C}$. Mixed arteriovenous blood was obtained after decapitation of the animals; the blood was centrifuged at $10,000 \mathrm{~g}$ for $10 \mathrm{~min}$, and the supernatant serum was stored at $-70^{\circ} \mathrm{C}$ until assayed for amylase activity.

Glutathione measurement. Frozen tissue samples were weighed rapidly and homogenized in 20 volumes $5 \%$ (wt/vol) sulfosalicylic acid. Allowing pancreas samples to thaw results in rapid and irreversible loss of glutathione. After centrifugation at $13,000 \mathrm{~g}$ for $3 \mathrm{~min}$, the total glutathione content (reduced and oxidized, GSH + GSSG) and oxidized glutathione content were determined in the supernatant by HPLC analysis of the glutathione-orthophthalaldehyde adduct (11). Briefly, to determine total glutathione, a mixture of $100 \mu$ l supernatant, $50 \mu \mathrm{l} 0.1 \mathrm{M}$ Tris, $\mathrm{pH} 8.5,50 \mu \mathrm{l} 0.8 \mathrm{M} \mathrm{NaOH}$, and $50 \mu \mathrm{l} 0.05 \mathrm{M}$ DTT was kept on ice for a period of $30 \mathrm{~min}$ to allow disulfide reduction. The mixture was diluted by addition of $0.75 \mathrm{ml}$ water and a $0.2-\mathrm{ml}$ aliquot was derivatized by mixing with $0.2 \mathrm{ml}$ orthophthalaldehyde, $5 \mathrm{mg} / \mathrm{ml}$ in $0.4 \mathrm{M}$ potassium borate, $\mathrm{pH}$ 9.4. After $1 \mathrm{~min}$, the solution was

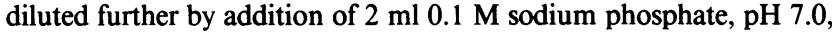
and a $120-\mu l$ aliquot was analyzed by HPLC. Oxidized glutathione was measured after first eliminating the reduced glutathione by treating the neutralized SSA supernatant with $0.5 \mathrm{mM}$ (final concentration) $N$-ethylmaleimide for $5 \mathrm{~min}$ followed by disulfide reduction with DTT as described above. The samples were eluted over a $\mathrm{C} 18$ reverse-phase column isocratically with $0.15 \mathrm{M}$ sodium acetate, $\mathrm{pH} 7.00$, containing $7.5 \%$ ( $\mathrm{vol} / \mathrm{vol})$ methanol. The derivative was detected fluorometrically by measuring emission at $420 \mathrm{~nm}$ with excitation at $340 \mathrm{~nm}$. Quantitation was performed by comparing derivative peak area to known standards.

Biochemical determinations. Pancreatic DNA content was determined with a fluorescent reagent (reagent 33258; Hoechst)(12). Pancreatic ATP content was determined using the firefly luciferase-luciferin assay (Los Alamos Diagnostics, Inc., Los Alamos, NM) and a Pico-Lite luminometer (Packard Instrument Co., Inc., Downers Grove, IL). Tissue $\gamma$ GT activity was determined as described by Swinnen (13). Serum was analyzed for amylase activity using the Phadebas test (Pharmacia Diagnostics, Inc., Fairfield, NJ).

Histologic grading. A pancreatic fragment from each animal was fixed in $10 \%$ buffered Formalin, embedded in paraffin, and sections stained with hematoxylin and eosin. Each sample was graded blindly for the extent of necrosis, vacuolization, and inflammation as described previously $(4,14)$.

Statistical analysis. Statistical significance was determined using analysis of variance and the Newman-Keuls test of multiple groups.

\section{Results}

Effect of caerulein treatment on pancreatic glutathione content. During the induction of acute pancreatitis in mice by caerulein administration, the total pancreatic glutathione content (reduced + oxidized) dropped precipitously. In mice adminis-

1. Abbreviation used in this paper: $\gamma \mathrm{GT}, \gamma$-glutamyltranspeptidase. tered caerulein, $50 \mu \mathrm{g} / \mathrm{kg}$ per h over $6 \mathrm{~h}$, the glutathione content dropped by $43 \%$ within the $1 \mathrm{st} h$ and after $4 \mathrm{~h}$, a nadir of $17 \%$ of normal was reached (Fig. 1). Glutathione content remained at this nadir while caerulein administration continued and began to rise after its discontinuation. After a 4-d convalescence period, the pancreatic glutathione content of these animals had recovered to normal. When glutathione content was determined relative to pancreatic DNA content rather than tissue weight, the same phenomenon was observed, with the glutathione content reaching a nadir of $27 \%$ of normal at $4 \mathrm{~h}$. The liver glutathione of these animals remained constant over the course of treatment in a range of 4 to $5 \mu \mathrm{mol} / \mathrm{g}$ liver (data not shown).

Lower doses of caerulein also caused a loss of pancreatic glutathione. When a dose of $0.1 \mu \mathrm{g} / \mathrm{kg}$ was given on the same schedule as the higher dose, pancreatic glutathione content fell to $68 \%$ of normal at $4 \mathrm{~h}$ (Fig. 1). Similarly, when mice were given the midrange dose of $5 \mu \mathrm{g} / \mathrm{kg}$, glutathione content fell to $30 \%$ at $4 \mathrm{~h}$. As with the highest dose, the glutathione content returned towards normal after discontinuing caerulein administration at these lower doses.

The intracellular redox equilibrium of glutathione usually favors the reduced form within tissues and this was found to be true in the pancreas as well. During the progression of pancreatitis in mice treated with $50 \mu \mathrm{g} / \mathrm{kg}$ caerulein, the fraction in the oxidized form was found to be $2.8-4.5 \%$ of the total glutathione content.

Effect of glutathione monoethyl ester during caerulein treatment. Glutathione monoethyl ester given before and during treatment with caerulein blunted the effect of caerulein on pancreatic glutathione content. Although caerulein still induced a significant drop in pancreatic glutathione in these animals, the nadir of $1.09 \mu \mathrm{mol} / \mathrm{g}$ was significantly higher than the nadir of $0.43 \mu \mathrm{mol} / \mathrm{g}$ in animals treated with caerulein alone in this experiment (Fig. 2). Histologic evidence of pancreatic injury in caerulein-treated mice was as described previously (4) with extensive inflammation, necrosis, and vacuolization evident

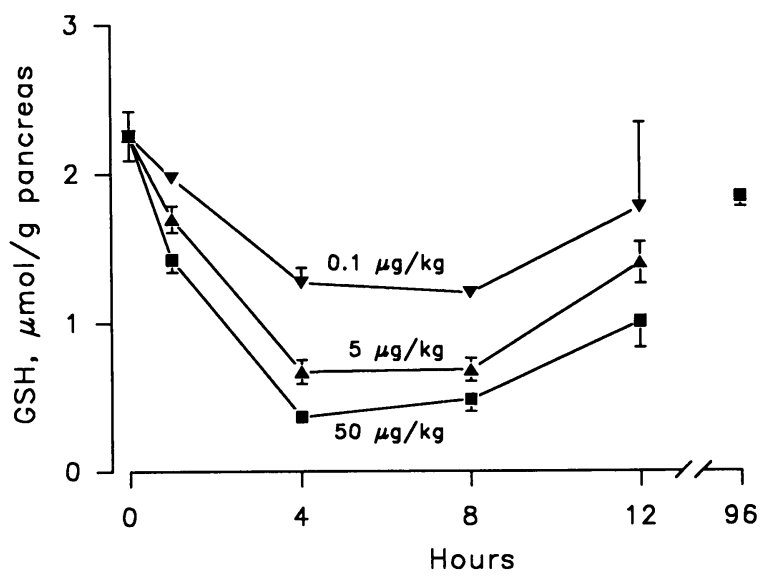

Figure 1. Pancreatic glutathione content (total, GSH + GSSG) in mice treated with caerulein, $0.1 \mu \mathrm{g} / \mathrm{kg}(\mathrm{v}), 5 \mu \mathrm{g} / \mathrm{kg}(\Delta)$, or $50 \mu \mathrm{g} / \mathrm{kg}$ (ש) s.c. hourly seven times beginning at $0 \mathrm{~h}$. Each point represents the mean of values from at least three animals; error bars represent SEM. Where error bars are not evident, they are concealed by the data point symbol. All values at 4 and $8 \mathrm{~h}$ are significantly less than at $0 \mathrm{~h}(P$ $<0.05$ ). At $4 \mathrm{~h}$, the pancreatic glutathione content of mice treated with $50 \mu \mathrm{g} / \mathrm{kg}$ is significantly less than mice treated with $0.1 \mu \mathrm{g} / \mathrm{kg}$ $(P<0.05)$. 


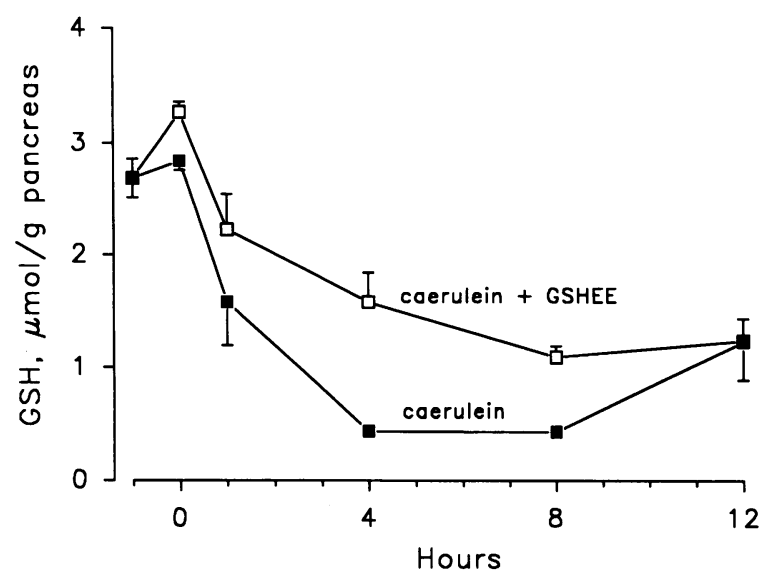

Figure 2. Pancreatic glutathione content in mice treated with caerulein, $50 \mu \mathrm{g} / \mathrm{kg}$ with and without concomitant treatment with glutathione monoethyl ester, $20 \mathrm{mmol} / \mathrm{kg}$ i.p. $1 \mathrm{~h}$ before beginning caerulein and $10 \mathrm{mmol} / \mathrm{kg} 3$ and $7 \mathrm{~h}$ after beginning caerulein. The pancreatic glutathione content in ester-treated animals was significantly greater than animals treated with caerulein alone at 0,4 , and $8 \mathrm{~h}$ after beginning caerulein $(P<0.05) . n \geq 3$ animals at each time point; error bars, SEM.

8-12 $\mathrm{h}$ after the initial caerulein injection (Table I, Figs. 3 and 4). In contrast, mice treated with glutathione monoethyl ester before and during caerulein treatment were found to have no evidence of pancreatic necrosis or inflammation at $8 \mathrm{~h}$ (Table I,

Table I. Pancreatic Histologic Changes in Mice Treated with Caerulein and Glutathione Monoethyl Ester

\begin{tabular}{|c|c|c|c|c|}
\hline \multirow[b]{2}{*}{ Time } & \multicolumn{4}{|c|}{ Histologic changes } \\
\hline & Vacuoles & Necrosis & Inflammation & Other \\
\hline \multicolumn{5}{|l|}{$h$} \\
\hline 0 & 0 & 0 & 0 & \\
\hline \multicolumn{5}{|l|}{1} \\
\hline -GSHEE* & 1 & 0 & 0 & \\
\hline +GSHEE ${ }^{\ddagger}$ & 0 & 0 & 0 & \\
\hline \multicolumn{5}{|l|}{4} \\
\hline -GSHEE & 1 & 1 & \pm & $\$$ \\
\hline +GSHEE & 1 & 0 & 0 & \\
\hline \multicolumn{5}{|l|}{8} \\
\hline -GSHEE & 1 & $1-2$ & 2 & $\$$ \\
\hline +GSHEE & 1 & 0 & 0 & $\S$ \\
\hline \multicolumn{5}{|l|}{12} \\
\hline -GSHEE & 2 & 2 & 2 & $\S$ \\
\hline +GSHEE & $1-2$ & 1 & 1 & $\$$ \\
\hline
\end{tabular}

The histologic grading of necrosis and vacuolization was based on the approximate fraction of cells involved: 0 , absent;,$\pm<5 \% ; 1,5-15 \%$;

$2,15-35 \% ; 3,35-50 \%$; grading of inflammation was based on a scale ranging from \pm as minimal to 4 as maximal alterations; at least three animals in each group.

* Animals treated with caerulein, $50 \mu \mathrm{g} \cdot \mathrm{kg}^{-1} \cdot \mathrm{h}^{-1}$, seven times with injections beginning at time 0 .

${ }^{\ddagger}$ Animals treated with caerulein + glutathione monoethyl ester, 20 $\mathrm{mmol} / \mathrm{kg} 1 \mathrm{~h}$ before beginning caerulein and $10 \mathrm{mmol} / \mathrm{kg} 3$ and $7 \mathrm{~h}$ after beginning caerulein.

${ }^{\S}$ Extensive edema and lobular disarray.
Fig. 5) and less than the untreated group at $12 \mathrm{~h}$ (Table I). Glutathione monoethyl ester appeared to be less protective against the appearance of vacuoles, edema, and lobular disarray (Table I).

Biochemical evidence of pancreatitis was determined by measuring serum amylase activity. In parallel with improvement in the histologic findings, treatment with glutathione monoethyl ester significantly diminished the degree of serum amylase elevation caused by caerulein treatment (Table II).

Potential causes of pancreatic glutathione loss. Further studies were undertaken to address several possible causes of the caerulein-induced pancreatic glutathione loss. The membranebound enzyme $\gamma$-GT (EC 2.3.2.1) is thought to be essential for glutathione precursor uptake in nonhepatic tissues by degrading extracellular glutathione and transporting the constituent amino acids across the cell membrane into the cell $(15,16)$. Activation of $\gamma \mathrm{GT}$ in the intracellular space could theoretically lead to inappropriate intracellular glutathione degradation; alternatively, diminished extracellular activity of this enzyme could result in decreased glutathione precursor uptake. The possibility that $\gamma$ GT was responsible for inappropriate intracellular glutathione degradation leading to the caerulein-induced loss was investigated by pretreating the animals with an inhibitor of the enzyme, AT 125 , which resulted in a 70\% reduction in pancreatic $\gamma$ GT activity. During caerulein administration to these animals, the loss of pancreatic glutathione actually appeared to be accelerated rather than prevented, as evidenced by a lower glutathione content at $1 \mathrm{~h}$ when compared with animals treated with caerulein alone (Fig. 6).

ATP is an essential substrate in the glutathione biosynthetic pathway. To evaluate its availability for intracellular glutathione synthesis, pancreatic ATP content was determined in caerulein-treated mice. As shown in Fig. 7, the ATP content dropped by $50 \%$ of normal after 4 and $12 \mathrm{~h}$ of caerulein; however, no diminution was found at $1 \mathrm{~h}$, a time at which glutathione content had already dropped by $43 \%$. Pancreatic ATP content returned to normal $4 \mathrm{~d}$ after caerulein treatment.

\section{Discussion}

The evidence that reactive oxygen species could have a significant role in the pathogenesis of acute pancreatitis is increasing. The initial studies of Cameron's group (17) led to reports by a number of other investigators demonstrating, either directly or indirectly, that species such as superoxide and hydrogen peroxide might be key elements leading to progressive tissue injury in acute experimental pancreatitis. The early studies in a perfused dog pancreas model with various insults to induce acute pancreatitis demonstrated reduced tissue edema and decreased amylase release when the perfusate also contained superoxide dismutase (SOD) and catalase $(8,18)$ or allopurinol $(8,19,20)$. Subsequently, similar observations were made using in vivo models of pancreatitis. Guice et al. (7) demonstrated decreased pancreatic edema and improved pancreatic histology when SOD and catalase were given to caerulein-treated rats; further investigation showed that catalase alone was also beneficial and that extravasation of catalase was essential for its protective effect (21). Similarly, Wisner et al. found that allopurinol (9) or SOD alone (without catalase) (22) decreased the amylase rise, decreased pancreatic edema, and improved pancreatic histology in caerulein-treated rats. 

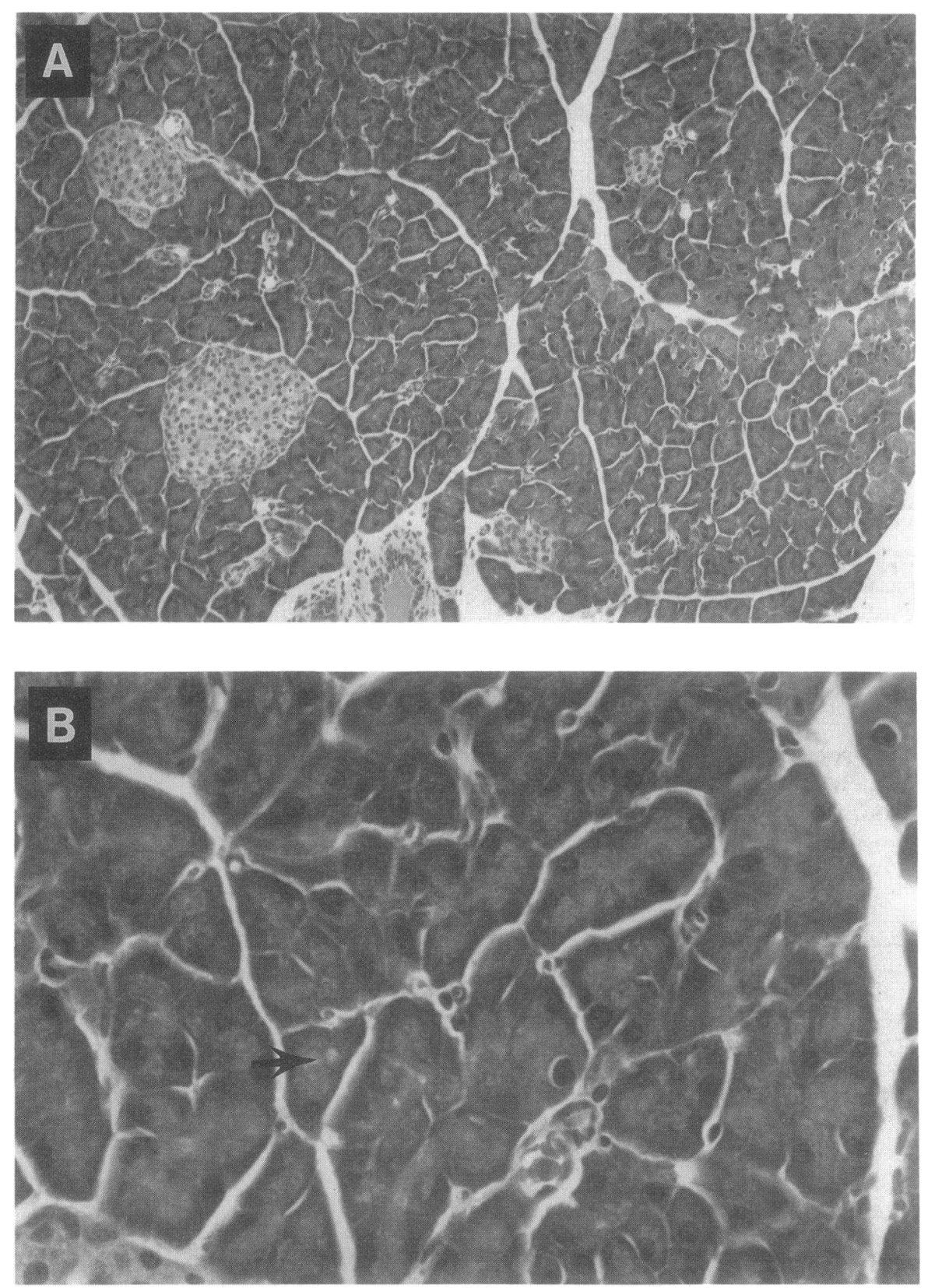

Figure 3. Pancreatic histology at time zero (no glutathione monoethyl ester). $(A)$ Low-power $(\times 125)$ view demonstrating normal pancreas with intact acini and paler-staining islets. Note the uniform rosette-like configuration and compact nature of the acini. $(B)$ Higher magnification $(\times 500)$ demonstrating tightly packed acini with the nuclei of acinar cells arranged at the periphery of the acini. The paler-staining central zone is the secretory area of the acinar cell. Note the rare vacuole (arrow).
The beneficial effects of SOD, catalase, and allopurinol described in these studies constitute indirect evidence that oxygen radicals may be involved in the pathogenetic mechanisms of acute pancreatitis. More direct evidence of radical-mediated processes occurring during pancreatitis has also been reported. Nonaka et al. (23) found increased indices of pancreatic lipid peroxidation in mice fed a choline-deficient, ethionine-supplemented diet. In the caerulein model of acute pancreatitis, recent studies have described elevations in several indices of oxidant stress, such as malondialdehyde $(24,25)$, conjugated dienes (24), and chemiluminescence (26).

This evidence for oxygen radical involvement in acute pancreatitis led us to examine elements of the endogenous cellular defense against these species. We now demonstrate that inducing pancreatitis in mice by caerulein administration causes a rapid drop in pancreatic glutathione content, a drop that precedes biochemical and histologic evidence of injury. This tem- poral relationship might suggest that glutathione loss is an early event leading to or potentiating pancreatic injury rather than a secondary phenomenon. Interestingly, moderate pancreatic glutathione depletion was also caused by caerulein when given at the physiologically stimulatory dose of $0.1 \mu \mathrm{g} / \mathrm{kg}$, a dose previously shown not to induce pancreatic injury as assessed biochemically or histologically (27). This finding further suggests that caerulein induces a loss of glutathione by a direct effect rather than as a consequence of injury. Despite the intracellular events leading to glutathione loss, the ability of the cell to maintain glutathione in a predominantly reduced state appears to remain intact.

The potentially critical role of pancreatic glutathione depletion in the processes leading to pancreatic injury was examined by augmenting the intracellular glutathione content with intraperitoneal administration of glutathione monoethyl ester. Whereas extracellular glutathione is unable to traverse the cell 

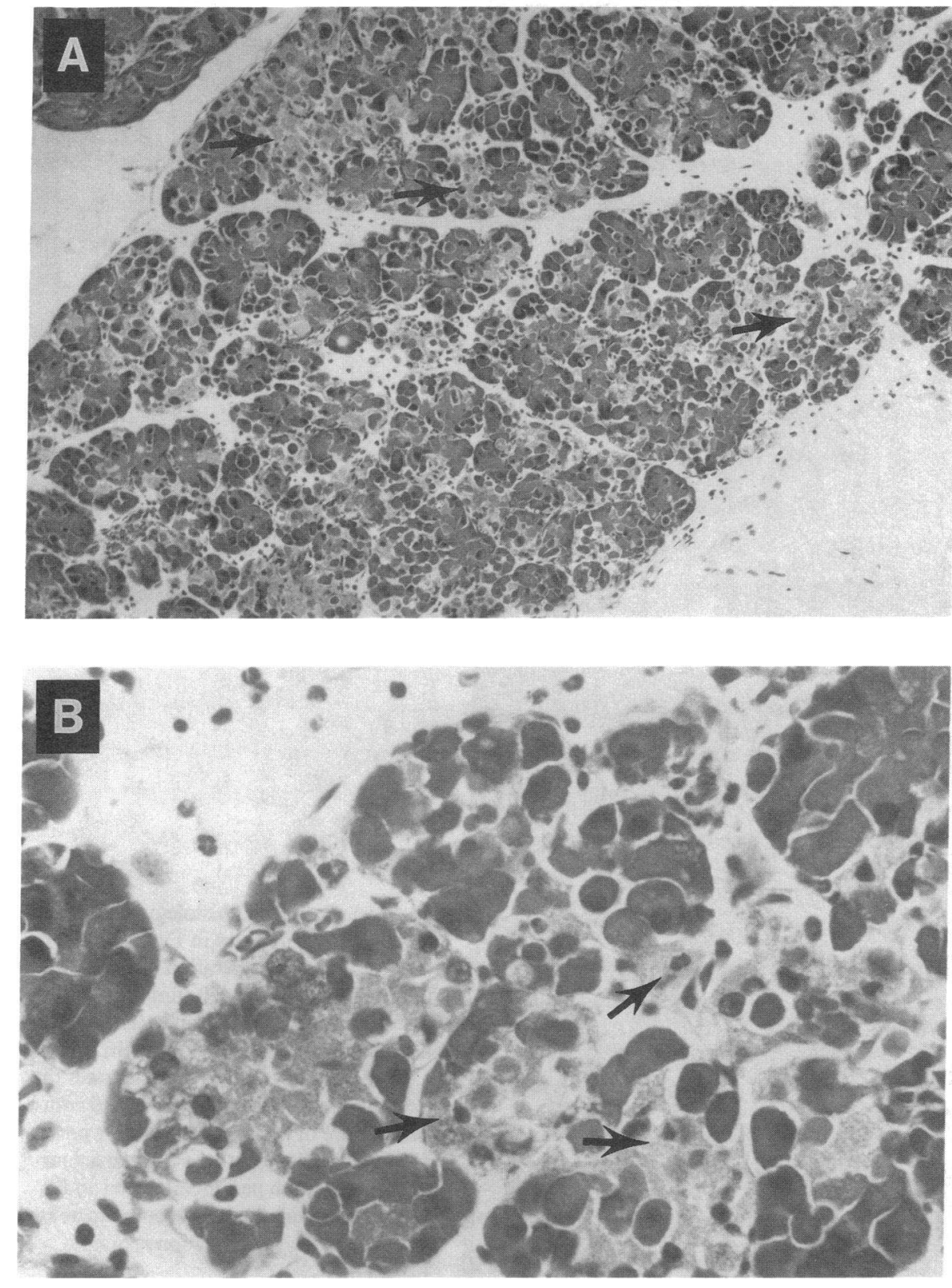

Figure 4. Pancreatic histology 8 h after beginning caerulein, $50 \mu \mathrm{g} / \mathrm{kg}$ per h s.c. seven times. $(A)$ Low-power view $(\times 125)$ demonstrates disruption of acinar architecture, focal acinar cell necrosis (arrows), inflammatory cells, and edema in the interstitial space. $(B)$ Higher power view $(\times 500)$ demonstrates disrupted acini with focal necrosis of the acinar cells as seen here in the pale-staining zones (arrows). The remaining acinar cells have lost their uniform orientation of the nuclei at the periphery, and the secretory zone is not prominent. Inflammatory cells are present (top left) seen best as small isolated nuclei in the interstitium. membrane intact $(15,16,28)$, the glycine-carboxyl ethyl ester of glutathione has been found to enter readily into the cytosolic space of a number of tissues, whereupon it undergoes hydrolysis to yield free glutathione (29). The precise mechanisms involved in transmembrane transport and subsequent ester cleavage are unknown. Nonetheless, this compound has proved to be an effective glutathione prodrug in a variety of experimental models. The pancreas appears to take up and hydrolyze glutathione monoethyl ester $(28,30)$ and in this study supraphysiologic levels of pancreatic glutathione were achieved $1 \mathrm{~h}$ after the first dose (Fig. 2).

The protection against histologic and biochemical evidence of pancreatitis afforded by concomitant glutathione monoethyl ester treatment supports a major role for glutathione in protecting against this mechanism of injury. It is unlikely that glutathione depletion alone is adequate for the production of pancreatitis; because pancreatitis has not been reported in studies of glutathione depletion, including one recent study of prolonged glutathione depletion in mice (28). Just as glutathione augmentation is found to be protective against caerulein-induced injury, glutathione depletion most likely exerts a permissive effect: when the intracellular glutathione content is depleted to a certain threshold, the yet-undefined mechanisms involved in caerulein-induced injury might then proceed unchecked. Although these mechanisms of injury are yet to be fully defined, the studies suggesting that generation of oxygen radicals is an important component of the events leading to pancreatitis is consistent with the present hypothesis that glutathione depletion exerts a permissive effect, which could be the generation of hydrogen peroxide and lipid hydroperoxides.

The events leading to the caerulein-induced glutathione depletion are not established. Any net loss of glutathione would 

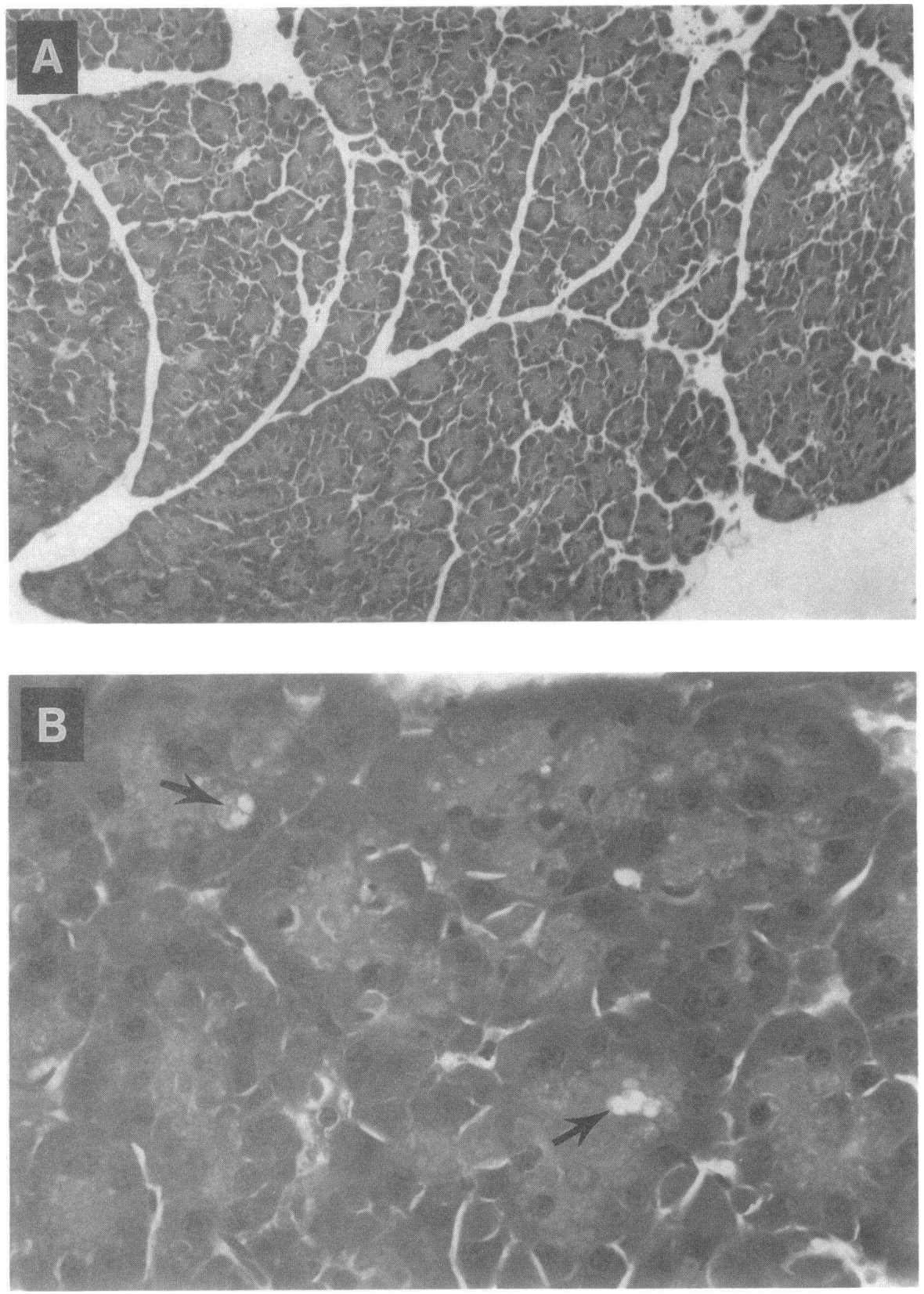

Figure 5. Pancreatic histology $8 \mathrm{~h}$ after beginning caerulein as in Fig. 4 but with concomitant administration of glutathione monoethyl ester, $20 \mathrm{mmol} / \mathrm{kg} 1 \mathrm{~h}$ before beginning caerulein and $10 \mathrm{mmol} / \mathrm{kg}$ 3 and $7 \mathrm{~h}$ after beginning caerulein. $(A)$ Low-power view $(\times 125)$ demonstrates the normal rosette-like architecture and compact nature of the acini. $(B)$ Higher power view $(\times 500)$ demonstrates normal acinar architecture with peripheral nuclei and central secretory zones, but some increase in cytoplasmic vacuolization is present (arrows). result from either inadequate synthesis or increased catabolism, the latter known to occur rapidly even in normal pancreas $(15,16,28)$. If caerulein induced a complete block in glutathione synthesis, the glutathione requirement from turnover should be met by the provision of glutathione monoethyl ester (28). In these studies this was not the case, because pancreatic glutathione levels fell in ester-treated animals, despite starting with supraphysiologic levels.

In addition to three precursor amino acids, glutathione synthesis also requires an adequate supply of ATP. The depletion of pancreatic ATP during caerulein treatment, although not profound, could exert an inhibitory effect on the overall rate of glutathione synthesis as the intracellular ATP content is near the $K_{\mathrm{m}}$ of the two enzymes in the glutathione-synthetic pathway (31). Nonetheless, implicating ATP depletion as a cause of the glutathione loss is difficult, as the ATP levels remain normal $1 \mathrm{~h}$ after the first caerulein injection, a time at which the glutathione content has dropped by $43 \%$. Thus, the observed ATP depletion later in the course of caerulein treatment most likely represents a secondary effect that may contribute to diminished GSH synthesis after depletion but does not cause depletion per se.

Rapid consumption or catabolism of glutathione are alternative explanations for the caerulein-induced pancreatic glutathione depletion. Irreversible consumption of glutathione can occur in an environment of ongoing lipid peroxidation (32). Reactive carbonyl lipid peroxidation products such as 4-hydroxynonenal react with glutathione to form stable conjugates; one proposed mechanism of peroxidative tissue injury is, indeed, the reaction of such species with essential intracellular components when the supply of glutathione has been depleted (32). If the caerulein-induced loss of pancreatic glutathione is occurring by this mechanism, it would suggest that the cause of oxidant stress is not glutathione depletion, but that glutathione 
Table II. Effect of Glutathione Monoethyl Ester Administration on Serum Amylase Activity During the Development of Caerulein-induced Pancreatitis

\begin{tabular}{lccccc}
\hline & \multicolumn{5}{c}{ Hours after beginning caerulein } \\
\cline { 2 - 6 } Treatment & 0 & 1 & 4 & 8 & 12 \\
\hline Saline & $56 \pm 4$ & $63 \pm 2$ & $84 \pm 2$ & $130 \pm 5$ & $177 \pm 13$ \\
GSHEE & & $72 \pm 4$ & $64 \pm 6$ & $78 \pm 4$ & $109 \pm 2$
\end{tabular}

Amylase values are expressed as $\mu \mathrm{g} / \mathrm{ml}$ serum. Values are means $\pm \mathrm{SD}$ of at least three animals at each time point. The amylase values of GSHEE-treated animals were significantly different from control animals at each time point $(P<0.05)$.

depletion is a result of the ongoing generation of reactive species. This is consistent with other models of lipid peroxidation where short-term glutathione depletion alone, without a source of oxidant stress, is not associated with peroxidative tissue injury.

The possibility that increased glutathione catabolism explains the caerulein-induced loss of glutathione cannot be eliminated. Little is known of normal intracellular breakdown of glutathione, if it occurs at all. The enzyme $\gamma \mathrm{GT}$ is a facile glutathione peptidase and is, in its usual orientation, exposed to the extracellular milieu of epithelial cells and thus unable to degrade the high intracellular glutathione content that most tissues maintain. The possibility that the usual orientation of this enzyme is altered by caerulein administration to allow intracellular glutathione breakdown was tested by inhibiting the activity of this enzyme. A 70\% inhibition of pancreatic $\gamma \mathrm{GT}$ activity did not blunt the fall in glutathione, suggesting that this enzyme is not responsible for the caerulein-induced loss of glutathione. In fact, inhibition of $\gamma \mathrm{GT}$ appeared to potentiate glutathione loss, a finding consistent with the idea that $\gamma \mathrm{GT}$ is important in transporting glutathione precursor amino acids across the cell membrane into the cytosolic compartment (15). Catabolism of intracellular glutathione by other mechanisms cannot be ruled out. Although glutathione is usually consid-

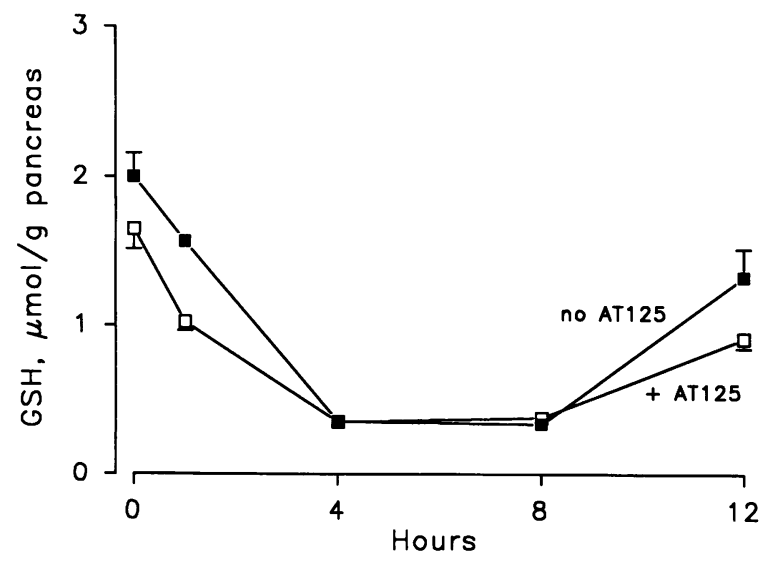

Figure 6. Pancreatic glutathione content in mice treated with caerulein, $50 \mu \mathrm{g} / \mathrm{kg}$ per h s.c. seven times, with and without concomitant treatment with AT125. Each point represents the mean of at least three animals. Error bars, SEM. GSH values at 1 and $12 \mathrm{~h}$ are significantly less in AT125-treated mice compared with controls at the same time point $(P<0.05)$.

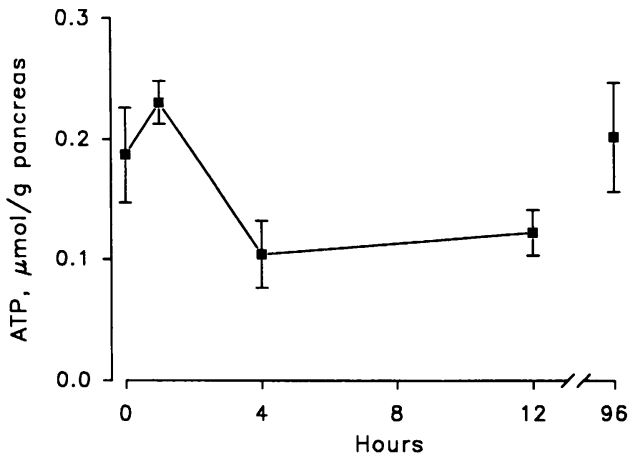

Figure 7. Pancreatic ATP content in mice treated with caerulein, 50 $\mu \mathrm{g} / \mathrm{kg}$ per $\mathrm{h}$ s.c. seven times. Each point represents the mean of at least three animals. Error bars, $1 \mathrm{SD}$ in each direction. ATP content at 4 and $8 \mathrm{~h}$ is significantly lower than initial ATP content $(P<0.05)$.

ered resistant to the actions of normal intracellular peptidases, an inappropriate intracellular release of pancreatic digestive enzymes could play a yet unrecognized role in glutathione loss. This possibility will be the subject of further studies.

\section{Acknowledgments}

The authors thank F. Joseph Roll for the use of the HPLC for glutathione analysis.

This study was supported by National Institute of Diabetes and Digestive and Kidney Diseases grants DK-38939 and DK-08324, and the American Philosophical Society Dalland Fellowship.

\section{References}

1. Steer, M. L., and J. Meldolesi. 1988. Pathogenesis of acute pancreatitis. Annu. Rev. Med. 39:95-105.

2. Grendell, J. H., and J. Egan. 1987. Acute pancreatitis. West. J. Med. 146:598-602.

3. Lampel, M., and H. F. Kern. 1977. Acute interstitial pancreatitis in the rat induced by excessive doses of a pancreatic secretagogue. Virchows Arch. A Pathol. Anat. Histopathol. 373:97-117.

4. Niederau, C., L. D. Ferrell, and J. H. Grendell. 1985. Caerulein-induced acute necrotizing pancreatitis in mice: protective effects of proglumide, benzotript, and secretin. Gastroenterology. 88:1192-1204.

5. Watanabe, O., F. M. Baccino, M. L. Steer, and J. Meldolesi. 1984. Supramaximal caerulein stimulation and ultrastructure of rat pancreatic acinar cell: early morphological changes during development of experimental pancreatitis. Am. J. Physiol. 246:G457-G467.

6. Koike, K., M. L. Steer, and J. Meldolesi. 1982. Pancreatic effects of ethionine: blockade of exocytosis and appearance of crinophagy and autophagy precede cellular necrosis. Am. J. Physiol. 242:G297-G307.

7. Guice, K. S., D. E. Miller, K. T. Oldham, C. M. Townsend, Jr., and J. C. Thompson. 1986. Superoxide dismutase and catalase: a possible role in established pancreatitis. Am. J. Surg. 151:163-169.

8. Sanfey, H., M. G. Sarr, G. B. Bulkley, and J. L. Cameron. 1986. Oxygenderived free radicals and acute pancreatitis: a review. Acta Physiol. Scand. Suppl. 548:109-118.

9. Wisner, J. R., and I. G. Renner. 1988. Allopurinol attenuates caerulein induced acute pancreatitis in the rat. Gut. 29:926-929.

10. Campbell, E. B., and O. W. Griffith. 1989. Glutathione monoethyl ester: high-performance liquid chromatographic analysis and direct preparation of the free base form. Anal. Biochem. 183:21-25.

11. Neuschwander-Tetri, B. A., and F. J. Roll. 1989. Glutathione measurement by high-performance liquid chromatography separation and fluorometric detection of the glutathione-orthophthalaldehyde adduct. Anal. Biochem. 179:236-241.

12. Labarca, C., and K. Paigen. 1980. A simple, rapid, and sensitive DNA assay procedure. Anal. Biochem. 102:344-352.

13. Swinnen, J. 1970. New colorimetric micromethod for the estimation of $\gamma$-glutamyltranspeptidase activity in biological samples. Z. Klin. Chem. Klin. Biochem. 8:557-559.

14. Niederau, C., R. A. Liddle, L. D. Ferrell, and J. H. Grendell. 1986. Benefi- 
cial effects of cholecystokinin-receptor blockade and inhibition of proteolytic enzyme activity in experimental acute hemorrhagic pancreatitis in mice. J. Clin. Invest. 78:1056-1063.

15. Griffith, O., and A. Meister. 1979. Glutathione: interorgan translocation, turnover, and metabolism. Proc. Natl. Acad. Sci. USA. 76:5606-5610.

16. Githens, S. 1991. Glutathione metabolism in the pancreas compared with that in the liver, kidney, and small intestine. Int. J. Pancreatol. 8:97-109.

17. Sanfey, H., G. B. Bulkley, and J. L. Cameron. 1983. Pathogenesis of acute pancreatitis: role of oxygen-free radicals. Surg. Forum. 34:222-224.

18. Sanfey, H., G. B. Bulkley, and J. L. Cameron. 1984. The role of oxygenderived free radicals in the pathogenesis of acute pancreatitis. Ann. Surg. 200:405-413.

19. Sanfey, H., G. B. Bulkley, and J. L. Cameron. 1985. The pathogenesis of acute pancreatitis. Ann. Surg. 201:633-639.

20. Sarr, M. G., G. B. Bulkley, and J. L. Cameron. 1987. Temporal efficacy of allopurinol during the induction of pancreatitis in the ex vivo perfused canine pancreas. Surgery. 101:342-346.

21. Guice, K. S., K. T. Oldham, and K. J. Johnson. 1989. Failure of antioxidant therapy (polyethylene glycol-conjugated catalase) in acute pancreatitis. $\mathrm{Am}$. J. Surg. 157:145-149.

22. Wisner, J., D. Green, L. Ferrell, and I. Renner. 1988. Evidence for a role of oxygen derived free radicals in the pathogenesis of caerulein induced acute pancreatitis in rats. Gut. 29:1516-1523.

23. Nonaka, A., T. Manabe, K. Tamura, N. Asano, K. Imanishi, and T. Tobe. 1989. Changes of xanthine oxidase, lipid peroxide and superoxide dismutase in mouse acute pancreatitis. Digestion. 43:41-46.
24. Schoenberg, M. H., M. Büchler, M. Gaspar, A. Stinner, M. Younes, I. Melzner, B. Bültmann, and H. G. Beger. 1990. Oxygen free radicals in acute pancreatitis of the rat. Gut. 31:1138-1143.

25. Dabrowski, A., and M. Chwiecko. 1990. Oxygen radicals mediate depletion of pancreatic sulfhydryl compounds in rats with caerulein-induced acute pancreatitis. Digestion. 47:15-19.

26. Gough, D. B., B. Boyle, W. P. Joyce, C. P. Delaney, K. F. McGeeney, T. F. Gorey, and J. M. Fitzpatrick. 1990. Free radical inhibition and serial chemiluminescence in evolving experimental pancreatitis. Br. J. Surg. 77:1256-1259.

27. Niederau, M., C. Niederau, G. Strohmeyer, and J. H. Grendell. 1989. Comparative effects of $\mathrm{CCK}$ receptor antagonists on rat pancreatic secretion in vivo. Am. J. Physiol. 256:G150-G157.

28. Martensson, J., A. Jain, and A. Meister. 1990. Glutathione is required for intestinal function. Proc. Natl. Acad. Sci. USA. 87:1715-1719.

29. Puri, R. J., and A. Meister. 1983. Transport of glutathione, as $\boldsymbol{\gamma}$-glutamylcysteinylglycyl ester, into liver and kidney. Proc. Natl. Acad. Sci. USA. 80:52585260.

30. Anderson, M. E., F. Powrie, R. N. Puri, and A. Meister. 1985. Glutathione monoethyl ester: preparation, uptake by tissues, and conversion to glutathione. Arch. Biochem. Biophys. 239:538-548.

31. Meister, A., and S. S. Tate. 1976. Glutathione and related $\gamma$-glutamyl compounds: biosynthesis and utilization. Annu. Rev. Biochem. 45:559-604.

32. Poot, M., A. Verkerk, J. F. Koster, H. Esterbauer, and J. F. Jongkind. 1987. Influence of cumene hydroperoxide and 4-hydroxynonenal on the glutathione metabolism during in vitro ageing of human skin fibroblasts. Eur. J. Biochem. 162:287-291. 